\begin{tabular}{|l|l|l||}
\hline \multicolumn{2}{|c|}{ PublisherInfo } \\
\hline \hline PublisherName & $:$ & BioMed Central \\
\hline \hline PublisherLocation & $:$ & London \\
\hline \hline PublisherImprintName & $:$ & BioMed Central \\
\hline \hline
\end{tabular}

\title{
Polymorphisms in drug metabolism
}

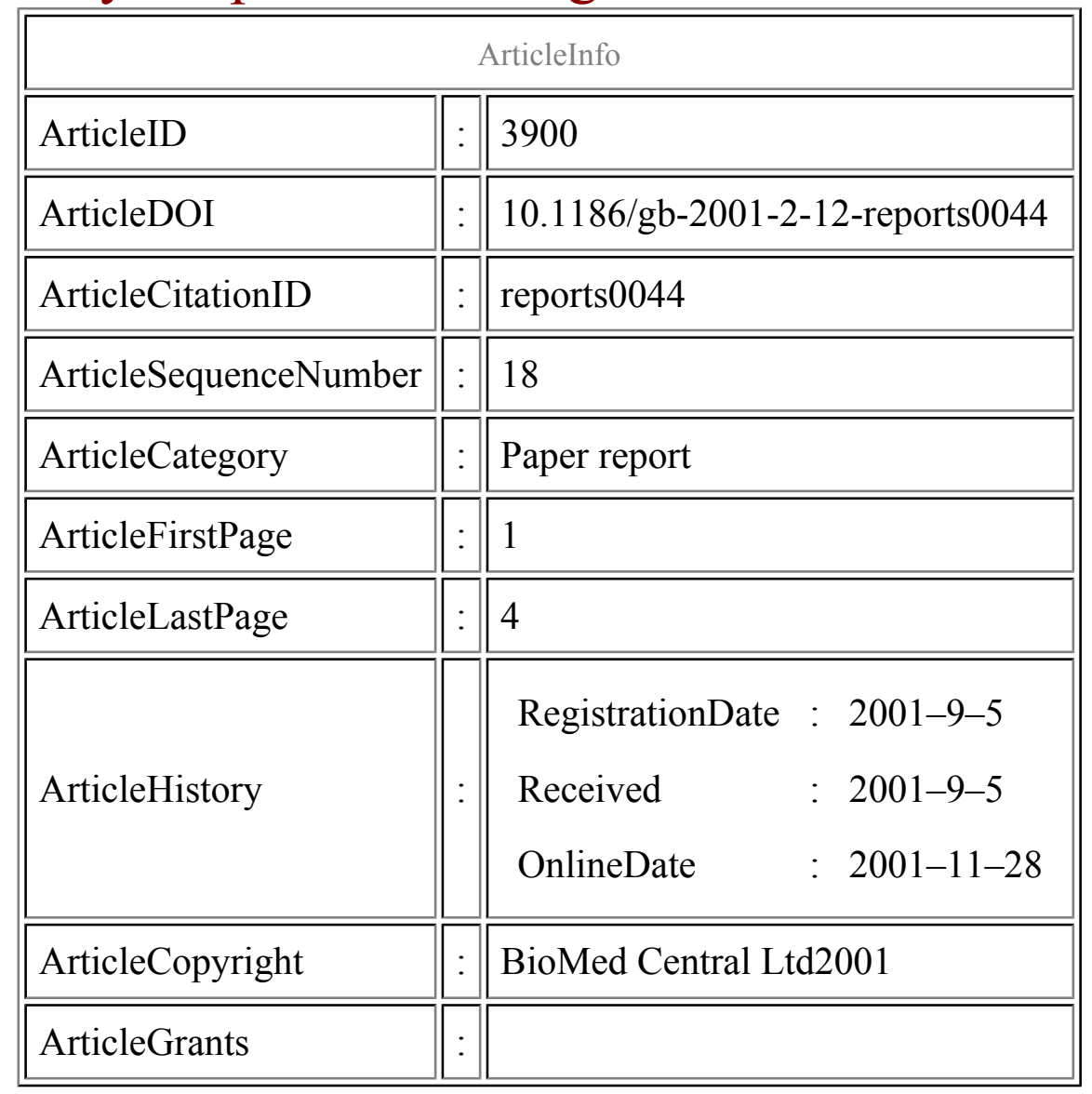




\begin{tabular}{|l|l|l|l|}
\hline ArticleContext & $:$ & 13059221212 \\
\hline
\end{tabular}

\section{John C Rockett}

\section{Abstract}

Systematic examination of the gene encoding CYP2B6, a human cytochrome P450, has characterized genetic polymorphisms that might account for its variability in expression and function between individuals.

\section{Significance and context}

Members of the cytochrome P450 family metabolize a plethora of structurally unrelated compounds, including retinoids, steroids and a variety of xenobiotics, such as carcinogens, toxins and drugs. There is increasing interest in the family member CYP2B6 as it has been shown to be involved in the metabolism of clinically important drugs (for example, bupropion, ifosfamide and tamoxifen) and substances of abuse (such as nicotine and the drug 'Ecstasy'). Many enzymes that metabolize xenobiotics have genetic polymorphisms that produce significant differences in the expression and/or activity of the protein product, which in turn can have profound effects on the success or otherwise of a drug therapy or response. The polymorphic variability of CYP2B6 has not previously been well characterized, and Lang et al. have started to address this issue by identifying polymorphisms and determining their frequency in over 200 German Caucasians.

\section{Key results}

Many genes in the CYP families are highly homologous, and in order to distinguish $C Y P 2 B 6$ from $C Y P 2 B 7$, specific intronic primer pairs were designed to cover each of the nine intervening exons. PCR amplicons produced from these primer pairs were sequenced directly to confirm that they were indeed derived from $C Y P 2 B 6$, and to determine polymorphic variation amongst a pool of 35 randomly selected German Caucasians. Diagnostic tests were developed from the sequence data analysis, using the fact that the single-nucleotide polymorphisms (SNPs) that were discovered either created or abolished a restriction enzyme site. It was thus possible to develop PCR-restriction fragment length polymorphism (RFLP) assays based on specific amplification of the SNP-containing exons coupled with a specific restriction digest.

Nine SNPs were found in the CYP2B6 sequences of the initial pool of (35) subjects, five of which were shown to result in amino-acid substitutions. The frequencies of these five changes were determined 
in a total of 215 randomly selected German Caucasians (including the initial pool), and found to occur in $0.5-32.6 \%$ of samples. Only 48 out of 215 subjects were found to be wild-type in context of these newly identified mutations. Significant differences were observed in protein production and enzymatic activity between carriers of some of the SNPs and the wild-type population.

\section{Links}

Further information on pharmacogenetics work at the authors' laboratory can be found at the $\mathrm{Dr}$ Margarete Fischer-Bosch - Institut für Klinische Pharmakologie website.

\section{Conclusions}

In terms of these newly identified SNPs, CYP2B6 appears to be one of the most polymorphic human P450s. The relatively high frequency and functional impact of one of the observed polymorphisms, $\mathrm{R} 487 \mathrm{C}$, may be useful in designing further studies on the clinical significance of this enzyme.

\section{Reporter's comments}

This work should be well received amongst the pharmacogenomics community, and indeed by anyone with an interest in xenobiotic metabolism or drug treatment. It would of course have been more informative and interesting if different ethnic groups could have been included in this study, but the cost and logistical problems associated with assembling such large human cohorts are often prohibitive. Nevertheless, now that that the PCR-RFLP conditions have been established and reported, the groundwork has been laid for future studies into polymorphic variations of the human CYP2B6 gene and their implications for differences in drug response among different ethnic populations and communities. Similar studies need to be carried out on other members of the CYP family and on other important drugmetabolizing enzymes such as the glucuronosyltransferases and glutathione- $S$-transferases. This study provides a valuable template for those considering such ventures.

\section{Table of links}

Pharmacogenetics

Dr Margarete Fischer-Bosch - Institut für Klinische Pharmakologie 


\section{References}

1. Lang T, Klein K, Fischer J, Nussler AK, Neuhaus P, Hofmann U, Eichelbaum M, Schwab M, Zanger UM: Extensive genetic polymorphism in the human CYP2B6 gene with impact onexpression and function in human liver. Pharmacogenetics. 2001, 11: 399-415. 0960-314X 